Enfermagem Brasil 2016;15(5):245-50

\title{
ARTIGO ORIGINAL \\ As representações sociais da mãe frente à morte de um filho e a assistência de enfermagem
}

Ivandira Anselmo Ribeiro Simões, M.Sc. ${ }^{*}$, Nayara Dias Andrade**, Wiviana Paiva Vilela de Oliveira** $^{* *}$

*Enfermeira, Professora da Escola de Enfermagem Wenceslau Braz, Itajubá/MG, **Graduanda
de Enfermagem na Escola de Enfermagem Wenceslau Braz, Itajubá/MG

Recebido em 17 de novembro de 2014; aceito em 11 de agosto de 2016.

Endereço de correspondência: Nayara Dias Andrade, Rua da Floresta, 233, 37500-234, Itajubá MG, E-mail: naydiasandrade@hotmail.com; Ivandira Anselmo Ribeiro Simões: ivandiranselmors@hotmail.com; Wiviana Paiva Vilela de Oliveira: wivivilela@hotmail.com

\section{Resumo}

Este estudo teve como objetivos compreender como as mães conseguiram passar pela situação da morte de um filho e identificar como foi a assistência prestada pelo enfermeiro no atendimento a esta mãe. Esta pesquisa foi aprovada pelo comitê de ética e pesquisa da Escola de Enfermagem Wenceslau Braz. É uma pesquisa qualitativa, descritiva, exploratória e transversal. As participantes foram 20 mães, a amostra foi do tipo bola de neve e o método utilizado foi Discurso do Sujeito Coletivo. Como resultados sobre a mãe frente à morte de um filho, identificamos cinco ideias centrais e dessas as que mais prevaleceram foram: "Muito Difícil", e "Muito Triste". E com relação ao enfermeiro na assistência prestada a mãe também cinco ideias centrais, das quais as duas que mais prevaleceram foram: "Não" e "Sim, enfermeira". Percebeu-se que não importa o motivo e quando a morte ocorreu, a dor vai ser a mesma, pois altera a ordem cronológica da vida que é os filhos enterrarem os pais e não ao contrário.

Palavras-chave: morte, Enfermagem, pesar.

\section{Abstract \\ Social representations of mothers facing death of a child and nursing care}

The objective of this study was to understand how mothers were able to get over the loss of a son or daughter, and to identify how the nursing care of mothers experiencing loss was. This research was approved by the Research Ethics Committees of Escola de Enfermagem Wenceslau Braz. It is a qualitative, descriptive, exploratory, cross-sectional research. The participants were 20 mothers. The snowball sampling and the Collective Discourse method were adopted. As a result on the topic of mother facing death of a child, we identified five central ideas, in which prevailed, "Very hard", and "Very sad". On the topic of nursing care of mother experiencing loss, we acquired five central ideas as well, in which the two prevailed were "No" and "Yes, Nurse". It was noticed that the motive or when the death occurred does not matter; the pain will be the same because it changes the chronological order of life that says sons/daughters bury their parents and not the other way around.

Key-words: death, Nursing, grief.

\section{Resumen \\ Las representaciones sociales de madres frente a la muerte de un hijo y los cuidados de enfermería}

Este estudio tuvo como objetivos comprender cómo las madres lograron pasar por una situación de muerte de un hijo, identificar cómo han sido los cuidados brindados por enfermeras a esta madre e identificar las características personales y sociales de las entrevistadas. Este estudio fue aprobado por el comité de ética e investigación de la Escuela de Enfermería Wenceslau Braz. Se trata de un estudio cualitativo, descriptivo, exploratorio y transversal con 20 madres. La técnica de muestreo bola de nieve y el método del Discurso del Sujeto Colectivo (DSC) han sido utilizados. Como resultados del tema de la madre frente a la muerte del niño, se identificaron cinco ideas centrales, y estas las que prevalecieron "Muy difícil" y "Muy triste". Y sobre el tema del enfermero en el cuidado de la madre que perdió un hijo también se encontraron cinco ideas centrales que prevalecieron "No" y "Sí, la enfermera". Se 
observó que no importa el motivo y cuando ocurrió la muerte, el dolor será el mismo, porque, por orden cronológico y natural, los hijos deben enterrar a sus padres y no al contrario.

Palabras-clave: muerte, Enfermería, pesar.

Introdução

Os maiores mistérios que circulam o ser humano se referem as suas origens, ao seu papel no mundo e a sua finitude. Para tentar explicá-los e compreendê-los, a humanidade vem procurando respostas através de conhecimentos filosóficos, científicos e religiosos. A morte não é apenas a destruição do estado físico e biológico, mas também o desaparecimento de um ser que interage, pois o vazio da morte é interacional, portanto, a ideia da morte traz a ruptura da interação da pessoa consigo mesma e da privação com sua comunidade e com sua cultura [1].

A ética da vida e da morte é única. O cuidado que damos ao nascer deve ser dado ao morrer, pois nascer e morrer fazem parte de um mesmo fenômeno: o da vida humana [2]. A morte tem dois lados. Um deles é a sua realidade física, e nisto todos se parecem. O outro são as palavras que dizemos uns aos outros, diante dela. É aqui que se encontra a diferença [3].

Para os pais que planejam e idealizam o futuro de seus filhos, a morte de um deles é um acontecimento indescritível. É como se esse planejamento desaparecesse de repente, como folhas levadas pelo vento. Algumas manifestações dão uma dimensão dessa perda avassaladora, como "o que será de nossas vidas sem ele ou ela" ou "nada mais terá sentido nas nossas vidas". Além do imensurável sofrimento, ocorre nesses pais todo tipo de sentimento: culpa, impotência, fracasso, raiva e punição [1].

Participar do processo de morrer é uma experiência única para qualquer ser humano, a maneira com que cada pessoa lida com a morte é reflexo de suas vivencias, seu grau de maturidade, seus valores culturais, espirituais e religiosos [1].

A superação do luto por parte dos pais é um processo de integração da criança morta à vida diária em que a dor da perda da criança nunca acaba apenas reduz [4]. O luto pode ser classificado em: crônico, que é o prolongamento indefinido do luto; inibido, quando há ausência dos sintomas normais de luto; e adiado, quando a pessoa não apresenta reações logo após a morte, apresentando um luto distorcido mais tarde [5].

Alguns fatores, como a morte violenta, repentina, muito sofrida ou que inverta a ordem natural das coisas, como o caso de filhos que morrem antes dos pais, podem agravar esse processo doloroso [6].

O profissional de Enfermagem precisa construir vínculos que possibilitem o olhar sobre os indivíduos, suas famílias e seu contexto de vida, entendendo como as famílias vivem, quem são, como são compostas, como se desenvolveram, como funcionam, que papéis desempenham, suas fragilidades e quais são as forças que os grupos familiares constituíram ao longo de sua trajetória para reconstruir o cuidado às famílias, reconhecendo-as, respeitando sua autonomia e favorecendo a resolução de seus problemas. Portanto, para se trabalhar com as famílias, é necessário que o profissional tenha conhecimento acerca do universo familiar, sem simplificá-lo, reduzindo-o a variáveis, relacionadas a condições de risco, em função de seus valores socioculturais [7].

Este estudo teve como objetivos: Compreender como as mães conseguiram passar pela situação da morte de um filho; Identificar como foi a assistência prestada pelo enfermeiro no atendimento a esta mãe.

Material e métodos

Estudo de abordagem qualitativa, descritiva, exploratória e transversal, realizado em duas cidades do sul de Minas Gerais. Teve como método de estudo o Discurso do Sujeito Coletivo (DSC), utilizando algumas figuras metodológicas como Expressões Chaves (ECH) e Ideia Central (IC). As participantes foram 20 mães que vivenciaram a morte de um filho. A amostragem foi do tipo proposital (intencional ou racional) e a amostra do tipo bola de neve.

Utilizou-se para a coleta de dados dois instrumentos: o primeiro destinado à identificação das características pessoais das mães, o qual é constituído de perguntas abertas e fechadas referentes à idade, escolaridade, situação conjugal, de trabalho e religião, motivo da morte do filho. O segundo trata de uma entrevista semiestruturada constituída de duas perguntas abertas. A primeira questão era sobre a experiência da mãe ao passar pela morte de 
um filho. A segunda relacionada à ajuda que as mães receberam pelos profissionais de saúde, principalmente o enfermeiro.

Esta pesquisa foi aprovada pelo Comitê de Ética e Pesquisa da Escola de Enfermagem Wenceslau Braz com o parecer consubstanciado número 114.669.

\section{Resultados}

Os resultados serão apresentados em dois quadros que permitirão visualizar os temas explorados e a frequência de cada Ideia Central.

Tema l: A mãe frente à morte de um filho

Quadro 1 - Ideias centrais sobre o tema I.

\begin{tabular}{|c|c|c|}
\hline \multicolumn{3}{|c|}{$\begin{array}{l}\text { Questão: Na sua vivência como mãe que presenciou a morte de um filho, como foi para você } \\
\text { passar por essa situação? }\end{array}$} \\
\hline & Participantes & Frequência da IC \\
\hline Muito dificil & $\begin{array}{l}1,2,3,5,7,8,12,13,14,15,1617, \\
18,19 \mathrm{e} 20\end{array}$ & 15 \\
\hline Muito triste & $10,12,15,16,18$ & 5 \\
\hline Hornivel & 11,14 & 2 \\
\hline Năo superei & 6 e 9 & 2 \\
\hline Sofri muito & 4 & 1 \\
\hline
\end{tabular}

Tema II: Enfermeiro na assistência da mãe que perdeu um filho

Quadro 2 - Ideias centrais sobre o tema II.

\begin{tabular}{|l|l|l|}
\hline Questão: Após essa morte, você recebeu alguma ajuda de algum profissional de saúde? \\
Mais especificamente da enfermagem? \\
\hline IC & Participantes & F requência da IC \\
Não & $4,6,8,11,13,15,16,18$ e 20 & 9 \\
Sim, enfermeira & $1,2,10,12,14$ e 17 & 6 \\
\hline Recebi de amigos e parentes & 3,7 e 19 & 3 \\
\hline Psicólogo & 5 & 1 \\
\hline Padre & 9 & 1 \\
\hline
\end{tabular}

\section{Discussão}

Ao analisarmos as ideias centrais do tema "A mãe frente à morte de um filho", observamos que a ideia mais frequente entre as participantes foi "Muito difícil". Há uma grande falta de preparação para o enfrentamento de tal perda, pois não se espera que pais enterrem seus filhos e sim, o contrário. Frente à perda de filhos, leva-se em conta a importância do vínculo e a proximidade de relacionamento implicados entre pais e filhos [8]. As mães assim se expressaram:

“... Para quem se prepara para construir uma família a perda de um filho é muito dura. Foi a situação mais difícil que enfrentei na minha vida, é uma dor incomparável...”.

A enfermeira deve se preparar para dar assistência à mãe que perde um filho. Passar pela perda de qualquer ente querido, não importando sua idade e nível de proximidade, é muito difícil. Pior, então, da perda de filhos, levando-se em conta a importância do vínculo e proximidade de relacionamento entre pais e filhos [8].

Dentro ainda desse tema, "Muito triste" foi outra ideia central muito usada pelas mães. A reação frente ao luto é particular de cada pessoa. Porém, ao relembrar da perda, esta sente uma intensa tristeza, mas é possível reencontrar um conforto [6]. Como podemos ver no seguinte discurso: 
"Mas foi muito triste, eu estava muito doente. Quando perdi foi muito triste. Foi bem traumatizante, tive muito sangramento que demorou a se conter e cheguei a ficar anêmica. Muito traumatizante. $A$ gente fica triste. A gente passa por momento de tristeza, porque a gente fica ansiosa querendo que venha. É muito triste."

A partir do momento que a pessoa aceita a realidade de ter perdido o ente querido, inicia-se uma tristeza profunda, pois a morte passa a ser uma realidade concreta e visível, 0 que provoca algumas manifestações, sejam elas físicas emocionais e espirituais. A tristeza é muito comum para aqueles que perdem seus entes. O que não pode ocorrer é esta tornar-se crônica [9].

Outra ideia central foi "Horrível", "Não Superei" e "Sofri muito". Esses foram evidenciados nos seguintes depoimentos:

\begin{abstract}
“... Eu não superei ainda, tá na saudade... Foi horrível. É uma experiência única e muito ruim... Eu fiquei sem chão, porque é horrível perder um filho, ainda mais quando você vê que está perfeito. Eu sofri muito com a morte do L...".
\end{abstract}

O processo de luto implica em reconhecer, aceitar a realidade, experimentar e lidar com as emoções resultantes da perda. Tais mudanças dependem de condições que favoreçam e/ou prejudiquem a elaboração dessa perda e, no entanto, demandam tempo. Trata-se de um tempo interno e não de um tempo cronometrado. O luto é único, singular e individual. A perda de uma pessoa querida desestrutura quem perde. É preciso aprender a viver sem a pessoa que morreu, porém há um tempo em que o hábito prevalece, e aqueles que iniciam o processo de luto ainda continuam a viver [3].

Ao interpretarmos as ideias centrais da questão: "Enfermeiro na assistência da mãe que perdeu um filho", a mais emergente foi "Não". Os profissionais da saúde têm se mostrado com falhas na formação quanto a esse tempo da vida para a morte. Poucos cursos abordam este assunto sobre a morte. Na parte prática são focados mais o doente, sua família e os cuidados que devem ser dados a eles, enquanto vivos. Portanto, na graduação o assunto morte quase não é discutido, e na vivência profissional é ainda pouco refletido [10]. Essa conclusão do autor pode ser interpretada diante o discurso das mães:

\footnotetext{
“... Não, de ninguém... Eu não recebi ajuda nenhuma, depois que sai do hospital, ninguém nunca me viu....".
}

Ao serem questionados sobre sua prática, é comum ouvirmos dos enfermeiros que "falta tempo" [11]. Essa é uma desculpa frequente, mas para realizar uma assistência de qualidade ele tem que se deslocar até a família, o paciente e ter a capacidade de ouvi-lo e isso requer tempo. Falta empenho dos enfermeiros para resgatar suas reais funções e redefinir seu valor profissional. Além disso, apesar de toda proposta lógica do processo de enfermagem, parece que a essência da profissão, a arte de cuidar, está em segundo plano. O que se vê é o enfermeiro assistencial desenvolvendo ações burocráticas, mergulhado em atividades rotineiras de controles e registros e perdendo a noção do seu principal papel que é cuidar [11].

Ainda sobre esse tema, obtivemos outra ideia central "Sim, enfermeira". Os enfermeiros relatam que, ao estabelecerem vínculo com os familiares e vivenciarem o sofrimento, também eles sofrem [12].

O enfermeiro é o profissional central da equipe de saúde, indispensável na assistência e está presente em todas as etapas do ciclo vital humano. Durante a assistência, deve perceber cada membro familiar a fim de buscar subsídios para efetivar a comunicação, sendo necessário adequar à forma de transmitir as informações de acordo com o contexto da família [13]. expressaram:

Este comentário condiz com o discurso de algumas mães entrevistadas que assim

“... Sim. Eu estava internada e lá no hospital a enfermeira veio e me orientou, falou o que tinha acontecido e me preparou... Recebi sim, por vários meses ainda. Em consequência da pressão alta mesmo, se existe meio AVC foi o que eu tive, pois um dia do nada meu braço caiu e fiquei uns 2 ou 3 meses com meu lado direito totalmente bobo, não conseguia fazer nada, nem pentear cabelo, abotoar camisa. Elas sempre iam, pelo menos duas vezes por dia iam dar assistência...”.

Dentro ainda desse tema, deparamos com a ideia central "Recebi de amigos e parentes". Alguns amigos aconselham aos pais que não fiquem falando sempre sobre a perda, 
mas sim se lembrar do filho de maneira significativa e isso talvez seja realmente o que eles precisam fazer [14].

Outra ideia central dentro desse mesmo tema foi "Padre". Os pais, ao falarem da perda dos filhos expressam que, a prece, a fé, conversa com sacerdotes ajuda a enfrentar a perda [14]. A afirmação desses autores vem de encontro com o discurso:

“... a única pessoa que veio conversar comigo foi um padre. Ele me orientou certinho, e eu to levando...".

A presença de um padre ou pastor serve de apoio e consolo para os que perdem o ente querido. $O$ fato é que as mães acreditam que pela sua fé a pessoa que morre vive para a vida eterna, logo serve de consolo a certeza de estarem vivos e com Deus.

Ainda sobre esse tema, encontramos a ideia central "Psicólogo". Hoje em dia, a morte ainda é vista como um tabu, cercada de mistérios e de crenças, e as pessoas, normalmente, não se encontram preparadas para lidar com morte. Quando esta ocorre de forma trágica e repentina, tende a causar várias alterações na vida de uma pessoa, ocasionando, muitas vezes, prejuízos e alterações, principalmente, emocionais e cognitivos. Neste momento, os enlutados poderão recorrer a um psicólogo e este tende a priorizar o acolhimento e a escuta ao paciente [15].

Essas palavras dos autores condizem com o que uma mãe explanou:

“... A única ajuda que eu tive foi com psicólogo...”.

O cuidado com os enlutados exige relacionamentos sofisticados e mais complicados de serem argumentados do que a aparente simplicidade dos modelos de cuidar. É um tipo de relacionamento que visa uma atenção às particularidades do enlutado, ajudando-os nesta difícil situação a enxergar que, às vezes, o que mais pode Ihes dar conforto é, ironicamente, falar sobre sua perda [15].

Considerando que a morte ainda não é bem aceita pela sociedade, percebeu-se que tratar desse tema não é fácil. O medo que esta causa para a maioria das pessoas é devido a não estarmos acostumados com o fato de que um dia morreremos, que esse fenômeno faz parte do ciclo vital, e também ao sentimento de fim e perda que é causado. Por esses motivos, não é fácil passar pela morte de um ente ou pessoa querida, o que faz com que as pessoas não entendam e tenham dificuldade em superá-la.

Assim, na maioria das vezes, o que ajuda a superar é a fé, a capacidade de acreditar em Deus e se esvaziar de si mesmo e ir ao encontro do outro, se ocupar.

Uma mãe que perde seu filho jamais será a mesma, sempre vai ter um pedaço vazio que era destinado aquele filho, porém é preciso encontrar forças e continuar, pois a vida não para diante dos sofrimentos. Lidar com o luto é muito difícil, pois cada um tem seu jeito, uma forma de encará-lo e superá-lo, não há regras para serem seguidas, apenas o seu coração.

Outros estudos devem ser realizados sobre o tema, pois há uma escassez de estudos nesta área. Há pesquisas sobre luto, morte e o processo morrer, porém o luto materno não é muito abordado.

\section{Referências}

1. Santos FS. Cuidados paliativos: discutindo a vida, a morte e o morrer. São Paulo: Atheneu; 2009.

2. Silva ACO, Nardi AE. Luto pela morte de um filho: utilização de um protocolo de terapia cognitivo-comportamental. Revista Psiquiátrica do Rio Grande do Sul 2010:32(2):113-6.

3. Alves EGR. A árvore: a difícil elaboração do processo de luto. O Mundo da Saúde 2012:36(1):127-32.

4. Either AM. Doença crônica e incapacitante ou cuidado em fim de vida para a criança e a família. In: Hockenberry MJ, Wilson D. Wong: Fundamentos de Enfermagem Pediátrica. São Paulo: Elsevier; 2011. p.589-625. 
5. Souza TRC. Morte e Luto: Desafio para o profissional de saúde. Disponível em URL: http://www.nhu.ufms.br/Bioetica/Textos/Morte\%20e\%200\%20Morrer/MORTE\%20E\%20 LUTO.pdf

6. Bousso RS. A complexidade e a simplicidade da experiência do luto. Acta Paul Enferm 2011:24(3):7-8.

7. Rodrigues CRF, Zioni F. Família como foco na atenção a saúde: Perspectiva da saúde da família. In: Ohara ECC, Saito RS. Saúde da família considerações teóricas e aplicabilidade. 2 ed. São Paulo: Martinari; 2010.

8. Rangel APFN. Dilemas éticos na morte do filhos. O Mundo da Saúde 2012;36(1):11-26.

9. Frias CFC, Pacheco S. O enfermeiro diante do processo de morrer, perdas e luto. Silva RS, Amaral JB, Malaguti W. Enfermagem em cuidados paliativos: cuidando da boa morte. São Paulo: Martinari; 2013. cap. 16, p. 281-8.

10. Schliemann AL. Aprendendo a lidar com a morte no ofício do profissional da saúde. In: Santos FS, ed. Cuidados paliativos: discutindo a vida, a morte e o morrer. São Paulo: Atheneu; 2009.

11. Oliveira SFD. Sistematizar é perder tempo? In: Silva MJP et al, eds. Qual o tempo do cuidado? Humanizando os cuidados de enfermagem. 2 ed. São Paulo: Loyola; 2006.

12. Lima AF. Doação de órgãos para transplante: conflitos éticos na percepção do profissional. O Mundo da Saúde 2012;36(1):27-33.

13. Paula MAB. Comunicação e tempo na Enfermagem em estomaterapia. Qual o tempo do cuidado? Humanizando os cuidados de enfermagem. 2 ed. São Paulo: Loyola; 2006.

14. Papalia DE, Feldman RD. Desenvolvimento Humano. $12^{\circ}$ ed. Porto Alegre: Artmed; 2013

15. Basso LA, Wainer R. Luto e perdas repentinas: contribuições da terapia cognitivocomportamental. Revista Brasileira de Terapias Cognitivas 2011;7(1):35-43. 